\title{
RECONHECIMENTO E HOMOLOGAÇÃO DE SENTENÇAS ESTRANGEIRAS: O PROJETO DE CONVENÇÃO DA CONFERÊNCIA DA HAIA
}

\author{
RECOGNITION AND ENFORCEMENT OF FOREIGN JUDGMENTS: THE “JUDGMENTS \\ PROJECT” OF THE HAGUE CONFERENCE ON PRIVATE INTERNATIONAL LAW
}

\section{Vera Lúcia Viegas Liquidato}

\author{
Doutora e Graduada pela Universidade de São Paulo (USP); \\ Professora Curso de Especialização em Direito Civil da \\ Faculdade de Direito da USP - Campus Ribeirão Preto; \\ Email: viegasliquidato@gmail.com
}

Recebido em: 13/10/2018

Aprovado em: 29/04/2019

\begin{abstract}
RESUMO: Não é de agora o esforço pela harmonização jurídica para trazer previsibilidade aos contratos internacionais. Considerando a diversidade de sistema jurídicos e que a circulação das mercadorias transpõe essas fronteiras, a segurança dessas relações, em muitos casos, passa pela necessidade de se conseguir executar uma sentença, alhures. Esse tema da homologação traz algumas indagações: seria viável pensar-se num sistema padronizado dos requisitos para homologação de decisões estrangeiras? Qual seria o foro de discussão adequado para esse desiderato? Considerando que há sistemas muito fechados às decisões estrangeiras - como o chinês - e outros mais abertos, é factível pensar que se poderia chegar a um consenso quanto à padronização desses requisitos? Este artigo enfrenta essas questões. Está prevista para 2019 a assinatura da Convenção sobre Homologação de Decisões Estrangeiras, fruto do trabalho da Conferência da Haia sobre Direito Internacional Privado. Trata-se do "Projeto de Sentenças" que objetiva simplificar a circulação de decisões, propiciando mais segurança nas transações econômicas. Este artigo oferece de modo claro, todo histórico desse "Projeto de Sentenças", até desembocar na véspera da Conferência Diplomática da Haia-2019. Comprovando a importância desse tema, basta mencionar dois trabalhos anteriores publicados na Revista da UniCeub anteriores à atual fase do "Projeto de Sentenças" - ambos intitulados "Crônicas de Direito Internacional Privado", sendo um de 2016 [v. 13, no 2, Gustavo Ferreira Ribeiro (et. al.)] e outro de 2017 [v. 14, nº 2, Nadia de Araujo (et. al.)]. Nas conclusões apresentar-se-ão de modo direto e sistemático, as vantagens e consequências da vindoura entrada em vigor dessa Convenção e os próximos passos da Conferência da Haia (o que já está em pauta hoje para futura negociação).
\end{abstract}

Palavras-chave: Conferência da Haia sobre Direito Internacional Privado; Homologação e Execução de Sentenças Estrangeiras; Direito Internacional Privado; Unificação jurídica. 
ABSTRACT: It is not from now on the effort for legal harmonization to bring predictability to international contracts. In view of the diversity of legal systems and the fact that the movement of goods transposes these frontiers, the safety of such relations in many cases goes hand in hand with the need to enforce a judgment, elsewhere. This issue of homologation brings some questions: would it be feasible to think of a standardized system of requirements for homologation? What would be the appropriate forum for discussion? Given that there are very closed systems for foreign decisions - such as chinese - and more open ones, is it feasible to think that consensus could be reached on the standardization of these requirements? This article addresses these issues. The signing of the Convention on the Enforcement of Foreign Judgments is expected in 2019, as a result of the work of the Hague Conference on Private International Law (PrIL). It is the "Judgments Project" that aims to simplify the circulation of decisions, providing more security in economic transactions. This article offers a clear, all-encompassing history of this "Judgments Project" until it ends on the eve of the 2019 Hague Diplomatic Conference. It is worth mentioning two other works published by UniCeub - previous to the current phase of the "Judgments Project" - both entitled "Chronicles of IPrL", one being from 2016 [v. 13, n 2, Gustavo Ferreira Ribeiro et al.) and another from 2017 [v. 14, $\mathrm{n}^{\mathbf{0}}$ 2, Nadia de Araujo (et al.)]. The conclusions will be presented in a direct and systematic way, the advantages and consequences of the forthcoming validity of this Convention and the next steps of the Hague Conference (which is already scheduled for future negotiations).

Key-Word: Hague Conference on Private International Law; Recognition and Enforcement of Foreign Judgments; Private International Law; Jurisprudence Unification.

SUMÁRIO: Introdução; 1 Alguns motivos que justificam a futura Convenção; 2 Trabalhos que antecederam o Projeto de Sentenças; 3 De 2016 até 2019; 4 Reunião de 24 a 29 de maio de 2018; Considerações Finais; Referências.

\section{INTRODUÇÃO:}

Este estudo tem por foco o Projeto de Convenção da Conferência da Haia sobre Reconhecimento e Homologação ${ }^{1}$ de Sentenças Estrangeiras ${ }^{2}$ em matéria civil e comercial (doravante chamado de:

\footnotetext{
${ }^{1} \mathrm{O}$ tema homologação de sentenças estrangeiras está regulamentado, no Brasil, no artigo 15 da Lei de Introdução às Normas do Direito Brasileiro (LINDB), bem como no Regimento Interno do Superior Tribunal de Justiça (Arts. 216A a Art. 216-N) e no Código de Processo Civil (Art. 963).

Sobre o histórico da LINDB, além das alterações substantivas ocorridas de 1916 a 2018, houve também alteração de sua nomenclatura. No primeiro Código Civil brasileiro ("Código Civil dos Estados Unidos do Brasil"), o nome era Introdução ao Código Civil (Lei n ${ }^{\circ} 3.071$, de $1^{\circ}$ de janeiro de 1916), nome esse que foi alterado para Lei de Introdução ao Código Civil (LICC) pelo Decreto-lei no 4.657, de 4 de setembro de 1942. Com a advento da Lei $\mathrm{n}^{\circ} 12.376$, de 30 de dezembro de 2010, de LICC passou para Lei de Introdução às normas do direito brasileiro, nome esse que permanece na atual Lei $\mathrm{n}^{\circ} 13.655$, de 25 de abril de 2018.

No que tange à competência para homologação de sentenças estrangeiras, a Emenda Constitucional (EC) $\mathrm{n}^{\circ} 45$ - de 30 de dezembro de 2004 -, transferiu-a do Supremo Tribunal Federal para o Superior Tribunal de Justica. Sobre o histórico da regulamentação pelo Regimento Interno do STJ (disponível em: https://ww2.stj.jus.br/publicacaoinstitucional/index.php/Regimento/issue/view/1/showToc - acesso em 26/12/2018), cumpre destacar, sobre o tema, a Resolução $\mathrm{n}^{\circ} 9$ do STJ, de 04 de maio de 2005 (disponível em: http://www.trtsp.jus.br/geral/tribunal2/Trib_Sup/STJ/Resol/9 05.html - acesso em 26/12/2018), revogada pela Emenda Regimental n 18 (de 19 de dezembro de 2014). Veja-se ainda sobre o tema, a Emenda Regimental no 24 de $\underline{2016 .}$

${ }^{2}$ Para uma análise de cunho prático do modus operandi para homologação de sentenças estrangeiras no Brasil, veja$\underline{\text { se o trabalho da Procuradora Federal: LOULA, Maria Rosa. Anotações sobre homologação de sentenças estrangeiras }}$
} 
"Projeto de Sentenças" 3), realizado sob os auspícios da Conferência da Haia sobre o Direito Internacional Privado.

Como a assinatura dessa Convenção está prevista para meados de 2019, é imprescindível que se faça um registro de todo o percurso até aqui, desde de onde surgiu essa ideia de criar um sistema padronizado para homologação de decisões estrangeiras, seus percalços, até desembocarmos no momento atual.

Faz-se mister explicitar os objetivos que se pretendem sejam alcançados com a entrada em vigor dessa Convenção.

Para cumprir esse desiderato, iniciaremos com um histórico do trabalho desenvolvido pela Conferência da Haia no Projeto de Sentenças (Judgments Project); analisar-se-á o trajeto já percorrido; considerar-se-ão os resultados obtidos até agora e os próximos passos a serem dados com a finalidade de se desembocar na realização de uma Conferência Internacional para aprovação desse Projeto de Sentenças, transformando-o assim numa Convenção: a Convenção da Haia sobre Reconhecimento e Homologação de Sentenças Estrangeiras e o que já se pretende após essa Conferência: quais serão os desdobramentos dos trabalhos a partir desse "ponto de chegada", ou seja, o que já está em pauta para a próxima negociação.

\section{ALGUNS MOTIVOS QUE JUSTIFICAM A FUTURA CONVENÇÃO}

O tema da homologação de sentenças estrangeiras é um dos temas centrais do Direito Internacional Privado ${ }^{4}$; representa um centro nevrálgico já que envolve o exercício da soberania nacional por meio da atuação do poder judiciário - que atua intra muros - ao proferir decisões às

no Brasil. In TIBURCIO, Carmen; VASCONCELOS, Raphael e MENEZES, Wagner (orgs.). Panorama do Direito Internacional Privado atual e outros temas contemporâneos: festschrift ao Professor Jacob Dolinger. Belo Horizonte: Arraes, 2015, p. 195-204. Sobre todo o histórico de como se deu a evolução da homologação de sentenças estrangeiras no Brasil desde 1822 até os dias atuais, veja-se GRUENBAUM, Daniel. A construção histórica do Reconhecimento de Sentenças Estrangeiras. In TIBURCIO, Carmen; VASCONCELOS, Raphael e MENEZES, Wagner (orgs.). Panorama do Direito Internacional Privado atual e outros temas contemporâneos: festschrift ao Professor Jacob Dolinger. Belo Horizonte: Arraes, 2015, p. 205-218, mais especificamente na p. 217. Ainda dentro de uma perspectiva histórica, sobre o reconhecimento de sentenças estrangeiras no direito alemão do século XIX, veja-se: FRICKE, Martin. Die autonome Anerkenungszuständigkeitsregel im deutschen Recht des 19. Jahrhunderts: zugleich ein Beitrag zur Entstehungsgeschichte von $§ 328$ Abs. 1 ZPO. Tübingen: Mohr, 1993.

3 A respeito do Projeto de Sentenças, há um rol bibliográfico disponibilizado pelo site da Conferência da Haia: CONFERENNCIA DA HAIA SOBRE DIREITO INTERNACIONAL PRIVADO. Bibliography Related to the Judgments Project: draw up by the Permanent Bureau. Disponível em: https://assets.hcch.net/docs/bd35517f-09ea47d6-95ad-865d2c162504.pdf [acesso em: 09/09/2018].

${ }^{4}$ Sobre esse assunto, a doutrina tem se debruçado consideravelmente. Para alguns estudos referentes ao tema, veja-se: ANZILOTTI, Dionisio. Studi di Diritto Processuale Internazionale e di Filosofia del Diritto. Vol. IV, Padova: Cedam, 1963 - em especial, capítulos 11: "Dei casi in cui è necessário il giudizio di delibazione di uma sentenza straniera" cap. 12: "Sulla idoneità delle sentenze straniere a produrre effetti in Italia, independentemente dal giudizio di delibazione", cap. 14: "Il riconoscimento delle sentenze straniere di divorzio in ordine alla seconda Convenzione dell'Aja 12 giugno 1902”. PINHEIRO, Luís de Lima. Estudos de Direito Internacional Privado: direito de conflitos, competência internacional e reconhecimento de decisões estrangeiras. Coimbra: Almedina, 2006. MOURA RAMOS, Rui Manuel. A Reforma do Direito Processual Civil Internacional. Coimbra: Coimbra Editora, 1998. PINHEIRO, Luís de Lima (org.). Seminário Internacional sobre comunitarização do Direito Internacional Privado: direito de conflitos, competência internacional e reconhecimento de decisões estrangeiras (realizado na Faculdade de Direito de Lisboa em 07 e 08 de maio de 2004). Coimbra: Almedina, 2005. CIVININI, Maria Giuliana. Il roconoscimento delle sentenze straniere: artt. 64-67 L. N. 218/1995. Milão: Giuffrè, 2001. TEBBENS, Harry (et. al.). Internationale Zuständigkeit und Urteilsanerkennung in Europa. Colônia/Berlim/Bonn/Munique: Carl Heymanns Verlag, 1993. 
quais se busca a produção de efeitos extra muros; passa pela consideração dos interesses nacionais (como em questões envolvendo competência jurisdicional exclusiva; teoria da exceção da ordem pública; imunidade de jurisdição, etc.) coadunados com o reconhecimento do direito que o Estado estrangeiro também tem de se pronunciar sobre relações jurídicas que transcendem fronteiras; o respeito a direitos adquiridos no estrangeiro; a consideração da coisa julgada, etc.

É importante que todo o esforço até agora empreendido nesse Projeto de Sentenças seja coroado de êxito com a aprovação da Convenção. Há que se ter plausibilidade nos requisitos necessários para viabilizar a execução de uma sentença estrangeira, inclusive no que tange ao controle indireto de jurisdição. ${ }^{5}$ A eficiência do comércio internacional repousa, dentre outros fatores, na necessária confiança recíproca entre as partes contratantes e essa confiança passa também pela certeza de que, caso haja um litígio num contrato internacional, a sentença proferida num Estado, produzirá efeitos também no outro Estado envolvido no caso. A ausência de normas uniformes internacionais gera imprevisibilidade no reconhecimento e execução de sentenças estrangeiras.

Gustavo Ferreira Ribeiro (et. al.) afirmam que o reconhecimento e execução de sentenças melhoram o acesso prático à justiça e relembram o Objetivo $\mathrm{n}^{\circ} 16$ das Nações Unidas para $\mathrm{o}$ Desenvolvimento Sustentável, qual seja: auxiliar no crescimento econômico com o incremento do comércio e investimento, já que haverá a redução de custos recorrentes de incertezas nas transações que exigem resolução judicial de litígios transfronteiriços. ${ }^{6}$

Cumpre destacar que esse Projeto de Sentenças não se ocupa de homologação de sentenças arbitrais $^{7}$; quem trata desse tema é a Convenção de Nova York sobre Reconhecimento e Execução

\footnotetext{
${ }^{5} \mathrm{Um}$ dos requisitos comumente exigidos para a homologação de sentenças estrangeiras é o de ter sido essa proferida por juiz competente; verificar esse requisito é justamente fazer o controle indireto de jurisdição. Homologar uma sentença estrangeira sem que se exija uma razoável conexão desse foro estrangeiro com o jurisdicionado brasileiro, é deixá-lo vulnerável a um juízo, por vezes, meramente oportunista. Vide, a respeito, De NARDI, Marcelo. Controle indireto da jurisdição internacional: a "autoridade competente" na homologação de sentenças estrangeiras no Brasil. Revista da ESMAFE/RS (Escola Superior da Magistratura Federal do RS), nº 1, Porto Alegre: ESMAFE/RS, 2017, p. 77-94.

${ }^{6}$ RIBEIRO, Gustavo Ferreira (et al.). Crônicas de direito internacional privado. Revista de Direito Internacional,

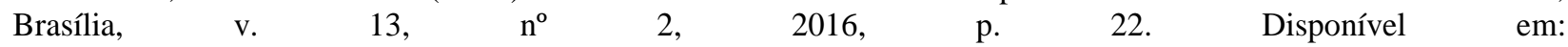
https://www.publicacoesacademicas.uniceub.br/rdi/article/view/4243/pdf [acesso em: 08/08/2018].

Nadia de Araujo e Marcelo De Nardi afirmam que: "[o] comércio internacional é o grande favorecido do anteprojeto de convenção, que diminuirá os custos das transações e conferirá certeza jurídica àqueles que expandem seus negócios pelo globo. Será mais fácil obter o respeito ao que foi acordado ou à indenização concedida se caírem as barreiras hoje existentes para que a sentença de um país seja reconhecida e executada em outro". ARAUJO, Nadia de; De NARDI, Marcelo. Desafios para a circulação de sentenças (notícia de 20/04/2018 do Jornal Valor Econômico). Disponível em: https://www.valor.com.br/legislacao/5468453/desafios-para-circulacao-global-de-sentencas [acesso em: 09/09/2018]. Texto completo da notícia disponível em: https://alfonsin.com.br/desafios-para-a-circulao-global-de-sentenas/ [acesso em: 09/09/2018].

${ }^{7}$ A respeito de homologação de sentenças arbitrais estrangeiras no Brasil, veja-se o trabalho hercúleo de Nadia de Araujo, que analisa os dez anos de atuação do Superior Tribunal de Justiça (STJ) na homologação de sentenças arbitrais estrangeiras, de 2005 em diante (quando a competência para homologação de sentenças estrangeiras foi transferida, como e viu, do Supremo Tribunal Federal - STF - para o STJ por força da EC $n^{\circ}$ 45/2004), oferecendo ao final do seu trabalho, um mui ilustrativo "Quadro Geral das Decisões em Homologação de Laudos Arbitrais Estrangeiros": ARAUJO, Nadia de. O STJ e a homologação de sentenças arbitrais estrangeiras: dez anos de atuação. In TIBURCIO, Carmen; VASCONCELOS, Raphael e MENEZES, Wagner (orgs.). Panorama do Direito Internacional Privado atual e outros temas contemporâneos: festschrift ao Professor Jacob Dolinger. Belo Horizonte: Arraes, 2015 , p. 155-180. Ainda sobre homologação de sentenças arbitrais estrangeiras, veja-se: CARAMELO, António Sampaio. O reconhecimento e execução de sentenças arbitrais estrangeiras perante a Convenção de Nova Iorque e a lei da arbitragem voluntária. Coimbra: Almedina, 2016.
}

Revista de Direito Brasileira | Florianópolis, SC | v. 22 | n. 9 | p.242-256 |Jan./Abr. 2019 
de Sentenças Arbitrais Estrangeiras, de 10 de junho de 1958, incorporada ao ordenamento jurídico brasileiro pelo Decreto Executivo n ${ }^{\circ} 4.311$ de 23 de julho de $2002 .{ }^{8}$ O que se pretende com o Projeto de Sentenças é justamente que também haja para a via judicial a segurança que se conseguiu para a circulação e homologação de laudos arbitrais estrangeiros, obtida por essa Convenção de Nova York de 1958.

\section{TRABALHOS QUE ANTECEDERAM O PROJETO DE SENTENÇAS}

Esse Projeto de Sentenças não foi o primeiro trabalho da Convenção da Haia ${ }^{9}$ no que tange à discussão de homologação de sentenças estrangeiras ou mais genericamente, à jurisdição e ao reconhecimento; ${ }^{10}$ mas foi o êxito com a Convenção sobre os Acordos de Eleição de Foro de 2005 ${ }^{8}$ Vide http://www.planalto.gov.br/ccivil 03/decreto/2002/D4311.htm [acesso em 15/08/2018].
${ }_{9}$ A Conferência da Haia sobre Direito Internacional Privado (The Hage Conference on Private International Law) é
hoje uma organização internacional que tem por escopo a unificação progressiva do Direito Internacional Privado,
atuando basicamente em três frentes: proteção à infância, negócios internacionais e aspectos processuais relativos à
cooperaçãa (vide site oficial: https://www.hcch.net - acesso em 06/08/2018; nesse site encontra-se lista com todas as
Convenções aprovadas pela Conferência da Haia e os Estados que delas fazem parte). A Conferência da Haia iniciou
essa sua missão por meio de convocações - primeiro pelo governo holandês - de Conferências (à primeira conferência,
ocorrida em 1893, compareceram 13 Estados). Em 1951, com a aprovação de seu Estatuto, adquire caráter permanente,
estabelecendo seu escritório permanente em 1955. Hoje conta 83 membros (82 Estados e a União Europeia). Vide, a
respeito desse histórico, CARVALHO RAMOS, André de. Direito Internacional Privado e a Ambição Universalista.
In TIBURCIO, Carmen; VASCONCELOS, Raphael e MENEZES, Wagner (orgs.). Panorama do Direito Internacional
Privado atual e outros temas contemporâneos: festschrift ao Professor Jacob Dolinger. Belo Horizonte: Arraes, 2015,
p. 14-33.

A Conferência da Haia não é a única iniciativa com essa finalidade. Ao lado dela, também com o escopo de uniformização das normas do Direito Internacional Privado, podem-se mencionar: o UNIDROIT (Instituto Internacional para a Unificação do Direito Privado), a UNCITRAL (Comissão das Nações Unidas para o Direito do Comércio Internacional), as Conferências Especializadas Interamericanas sobre Direito Internacional Privado (CIDIPs), a Comissão Internacional do Estado Civil (CIEC). A respeito, vide, VIEGAS, Vera Lúcia. Harmonização Jurídica e Direito de Integração: elementos para uma teoria da Harmonização Jurídica. Tese (Doutorado). Faculdade de Direito - Departamento de Direito Internacional e Comparado - Universidade de São Paulo (USP), São Paulo, 2003, p. 73-79.

Cumpre lembrar que nem todos esses organismos trabalham exatamente na tarefa de unificação legislativa. A propósito, veja-se, nessa mesma tese supracitada, a classificação apresentada à p. 52, diferenciando as categorias de: aproximação jurídica, harmonização jurídica, coordenação jurídica, unificação de elementos de conexão, reconhecimento mútuo de legislações e unificação legislativa [VIEGAS, 2003, 49-52]. Já para uma classificação das técnicas de produção das normas de harmonização jurídica, com os critérios de: origem da atividade de produção das normas de harmonização jurídica (p. 135), critério da força jurídica do instrumento escolhido para a harmonização (p. 136), critério do objetivo visado pela norma de harmonização (p. 138), o critério do momento da realização da harmonização (p. 140) e do critério do conteúdo do ato de harmonização e da harmonização de procedimentos (p. 141), veja-se [VIEGAS, 2003, 135-142].

${ }^{10}$ Desde 1893 (data da sua fundação), cumpre sejam destacadas, dentre outras, apenas a título ilustrativo, as seguintes Convenções: Convenção sobre Reconhecimento e Execução de Sentenças Estrangeiras em matéria Civil e Comercial, de 01\%02/1971 (com o seu Protocolo Suplementar de 01\%/02/1971); Convenção Relativa ao Reconhecimento e Execução de Decisões em Matéria de Prestação de Alimentos a Menores, de 15/04/1958, cuja entrada em vigor se deu em 01\%01/1962 - o Brasil, porém, não faz parte - sobre questionários da Conferencia da Haia e respostas do governo brasileiro, referente a essa convenção, vide https://www.hcch.net/pt/instruments/conventions/publications1/?dtid=33\&cid=38 - acesso em 15/08/2018; Convenção sobre a Jurisdição, Lei Aplicável e Reconhecimento de Decisões em Matéria de Adoção, de 15/11/1965; Convenção concernente ao Reconhecimento e Execução de Decisões Relativas às Obrigações Alimentícias, de 02/10/1973; Convenção sobre Celebração e Reconhecimento da validade dos Casamentos, de 14/03/1978; Convenção 
${ }^{11}$ que fez com que os trabalhos de uma ideia lançada pelos EUA na Conferência da Haia de 1992, trabalhos esses que haviam sido interrompidos em 2001, fossem retomados.

$\mathrm{Na}$ verdade, a partir de 1992 com essa ideia lançada pelos EUA, o desenrolar dos trabalhos de negociação com a finalidade de obtenção de uma Convenção sobre Reconhecimento e Homologação de Sentenças Estrangeiras, deparou-se com dificuldades tais para consenso sobre temas fundamentais, o que levou a uma redução da abrangência do objeto, que passou a ser especificamente "Acordos de Eleição de Foro", desembocando na assinatura da Convenção da Conferência da Haia sobre Acordos de Eleição de Foro de 30 de junho de $2005^{12}$, cujo Artigo $8^{\circ}$ e ss. estatuem regras sobre o dever de reconhecimento de sentenças estrangeiras proferida no foro que foi exclusivamente eleito. Daqui percebeu-se que decorre um potencial para que se consiga uma uniformização das normas sobre reconhecimento e homologação de sentença estrangeiras.

\section{Conforme informam RIBEIRO, Gustavo Ferreira (et. al.):}

A aprovação da Convenção sobre Eleição de Foro de 2005 pelo Conselho de Assuntos Gerais da Conferência da Haia de Direito Internacional Privado encerrou um primeiro ciclo de trabalho do Projeto de Sentenças. No ano de 2011, o Conselho de Assuntos Gerais estabeleceu nova diretriz para retomada do projeto, dada a receptividade alcançada por essa Convenção e o incremento das expectativas globais sobre o tema. Após recomendação de um grupo de especialistas reunido em 2012, o Conselho estabeleceu novo grupo de trabalho que, após cinco reuniões presenciais, finalizou o anteprojeto discutido na Comissão Especial de 2016. O Brasil esteve representado em todas as oportunidades. ${ }^{13}$

Relativa à Lei Aplicável ao Trust e ao seu Reconhecimento, de 01\%07/1985; Convenção sobre Jurisdição, Direito Aplicável, Reconhecimento, Execução e Cooperação com respeito à Responsabilidade Parental e Medidas de Proteção às crianças, de 19/10/1996; Convenção sobre a Cobrança Internacional de Alimentos para Crianças e outros Membros da Família, de 23/22/2007 (essa Convenção e seu Protocolo sobre Lei Aplicável às Obrigações de Prestar Alimentos, foram promulgados no Brasil pelo Decreto Executivo $\mathrm{n}^{\circ}$ 9.176, de 19/10/2017; disponível em: http://www.planalto.gov.br/ccivil 03/ ato2015-2018/2017/decreto/D9176.htm - acesso em 20/08/2018), etc.

${ }^{11}$ Essa Convenção foi oferecida para a ratificação de Estados não membros da Conferência da Haia e entrou em vigor em 01\%10/2015. O Brasil não faz parte dessa Convenção. Fazem dela parte: Alemanha, Áustria, Bélgica, Bulgária, Chipre, Croácia, Dinamarca (desde 01\%09/2018), Eslováquia, Eslovênia, Espanha, Estônia, Finlândia, França, Grécia, Hungria, Irlanda, Itália, Letônia, Lituânia, Luxemburgo, Malta, México, Montenegro (desde 01\%/08/2018), Países Baixos, Polônia, Portugal, Reino Unido da Grã Bretanha e Irlanda do Norte, República Tcheca, Romênia, Singapura (desde 01\%10/2016), Suécia e União Europeia. Estados que assinaram, porém ainda não ratificaram: EUA (assinou em 19/01/2009), Ucrânia (21/03/2016) e China (12/09/2017). Para a lista completa, vide: CONFERÊNCIA DA HAIA SOBRE DIREITO INTERNACIONAL PRIVADO. CONVENÇÃO SOBRE OS ACORDOS DE ELEIÇÃO DE FORO. Disponível em: https://www.hcch.net/pt/instruments/conventions/status-table/?cid=98 [acesso em $01 \% 1 / 2019]$.

${ }^{12}$ Para mais informações a respeito da Convenção da Haia sobre Acordos de Eleição de Foro, veja-se seu Relatório Explicativo, feito pelos professores Trevor Hartley e Masato Dogauchi: HARTLEY, Trevor; DOGAUCHI, Masato. Convention of 30 June 2005 on choice of court agreements: explanatory report. A Haia: Secretariado da Conferência da Haia sobre Direito Internacional Privado, 2005. Disponível em: https://assets.hcch.net/upload/expl37final.pdf [acesso em 20/08/2018]. Para o texto em outros idiomas, inclusive em língua portuguesa, veja-se: https://www.hcch.net/pt/publications-and-studies/details4/?pid=3959 [acesso em 20/08/2018].

${ }^{13}$ RIBEIRO, Gustavo Ferreira (et. al.). Crônicas de direito internacional privado. Revista de Direito Internacional, Brasília, v. 13, n.2, 2016, p. 19. 
Pode-se dizer que a Conferência da Haia promove o Projeto de Sentenças desde 2012, mas já com uma bagagem que remonta a período até anterior aos trabalhos para a Convenção de Eleição de Foro de 2005. ${ }^{14}$

Do aludido na citação acima depreende-se que, para tocar o Projeto de Sentenças a partir das novas diretrizes ditadas pelo Conselho de Assuntos Gerais, em 2011, foi estabelecido um Grupo de Trabalho - do qual o Brasil foi membro - formado por representantes de diversos países, ${ }^{15}$ cuja missão era apresentar uma primeira minuta do texto da Convenção. Após cinco reuniões presenciais, esse grupo de trabalho finalizou o texto do Projeto. ${ }^{16}$

Quanto à participação do Brasil nas cinco reuniões presenciais desse grupo de trabalho, cumpre destacar que o Brasil formulou contribuições de natureza técnica, relatando experiências nacionais sobre a matéria [RIBEIRO et al., 2016: 20]. ${ }^{17}$

Com a finalização da tarefa desse grupo de trabalho com a elaboração da minuta do Projeto, foi então estabelecida uma Comissão Especial em 2016 para discuti-lo (a Comissão Especial sobre o Reconhecimento e Homologação de Sentenças Estrangeiras, ou simplesmente, Comissão Especial sobre o Projeto de Sentenças: Special Commission on the Judgments Project). ${ }^{18}$

\footnotetext{
${ }^{14}$ Prova disso é a existência de bibliografia específica sobre uma Convenção geral de reconhecimento e homologação de sentenças estrangeiras ser encontrada a partir de, no mínimo, 1993. Daniel Gruenbaum, na nota de rodapé nº 77 do seu trabalho já aqui citado, traz autores que se debruçaram sobre o tema. Cita vários trabalhos de Arthur T. von Mehren, publicados nesta sequência: 1993, 1994, 1997 e 2001; cita também outros autores, com trabalhos publicados nestas datas: Haimo Schack (1993); Andreas F. Lowenfeld (1994); Peter Trooboff (1996); Catherine Kessedjian (trabalhos de 1997 e 2001) e Peter E. Nygh (2001). GRUENBAUM, Daniel. A construção histórica do Reconhecimento de Sentenças Estrangeiras. In TIBURCIO, Carmen; VASCONCELOS, Raphael e MENEZES, Wagner (orgs.). Panorama do Direito Internacional Privado atual e outros temas contemporâneos: festschrift ao Professor Jacob Dolinger. Belo Horizonte: Arraes, 2015, nota de rodapé 77 (p. 218).

${ }^{15}$ Gustavo Ferreira Ribeiro et al. informam que: "[o] grupo de trabalho era composto por especialistas dos Estadosmembros da Conferência da Haia indicados para essa tarefa específica". In [RIBEIRO et al., 2016:19].

${ }^{16}$ Para um histórico completo das origens dos trabalhos para o Projeto de Sentenças, veja-se CONFERÊNCIA DA HAIA SOBRE DIREITO INTERNACIONAL PRIVADO. COMISSÃO ESPECIAL SOBRE RECONHECIMENTO E EXECUÇÃO DE SENTEÇAS ESTRANGEIRAS (Special Commission on the Judgments Project). Judgments Convention: Revised Preliminary Explanatory Report (Fourth Meeting of the Special Commission on the Recognition and Enforcement of Foreign Judgments 24-29 May 2018). Disponível em: https://assets.hcch.net/docs/7cd8bc44-e2e546c2-8865-a151ce55e1b2.pdf [acesso em 20/08/2018].

${ }^{17}$ RIBEIRO et al. informam ainda aqui "Marcelo De Nardi participou das $2^{\text {a }}$ a $5^{\text {a }}$ reuniões do Grupo de Trabalho, por indicação do governo brasileiro, preparou manifestações técnicas de avaliação e sugestões no período, além de ter comparecido junto com Nadia de Araujo a vários eventos realizados no Brasil a respeito do tema. Para a primeira reunião da Comissão Especial, preparou um documento informativo sobre proteção ao consumidor" [RIBEIRO et al., 2016: 20]. Sobre o conteúdo material dessa minuta, e os assuntos que seriam de interesse do Brasil e exigiriam, portanto, atenção e estudo, veja-se [RIBEIRO et al., 2016: 22]. Dentre esses assuntos, estão: definição da expressão "questões civis e comerciais" (esse é o objeto da Convenção), definição de "consumidor", filtros indiretos de jurisdição, tema da propriedade intelectual, o tema da jurisdição exclusiva, etc. Para maiores considerações sobre as discussões em torno do tema propriedade intelectual, veja-se ARAUJO, Nadia de; De NARDI, Marcelo. Crônica 1. Novidades de 2017 sobre circulação facilitada de sentenças estrangeiras. In ARAUJO, Nadia de (et al.). Crônicas de direito internacional privado. Revista de Direito Internacional, Brasília, v. 14, no 2, 2017, p. 11-14.

Ainda acerca da participação da Nadia de Araujo e Marcelo de Nardi em eventos no Brasil sobre o Projeto de Sentenças, veja-se reunião realizada no INPI (Instituto Nacional de Propriedade Intelectual), em 01\%09/2017. INSTITUTO NACIONAL DA PROPRIEDADE INDUSTRIAL. Ministério da Indústria, Comércio Exterior e Serviços. INPI sedia debate sobre PI no projeto de sentenças estrangeiras. Disponível em: http://www.inpi.gov.br/noticias/inpi-sedia-debate-sobre-pi-no-projeto-de-regime-global-de-circulacao-de-sentencas acesso em 09/09/2018. A apresentação deles nessa reunião, em power point, está disponível em: http://nadiadearaujo.com/wp-content/uploads/2017/09/INPI_1set17.pdf [acesso em 09/09/2018].

${ }^{18}$ A base para o início do trabalho dessa Comissão Especial criada em 2016 foi justamente essa minuta apresentada pelo Grupo de Trabalho.
} 
Essa Comissão se reuniu por quatro vezes, tendo sido a sua quarta e última reunião, em maio de 2018 (de 24 a 29/05/2018). De cada uma dessas reuniões surgiu um Projeto condensando os pontos sob os quais chegou-se a um consenso e os pontos que permaneciam ainda em aberto. ${ }^{19}$

\section{DE 2016 ATÉ 2019}

Conforme visto no item 3 supra (3. Trabalhos que antecederam o Projeto de Sentenças), percebe-se que a cronologia dos trabalhos desenvolvidos passa pelo momento histórico do surgimento da ideia de se estudar o assunto; solução de continuidade do Projeto (lapso de tempo na qual houve a interrupção dos trabalhos); êxito na negociação da Convenção sobre Acordos de Eleição de Foro que reacende a chama do Projeto e acarreta a retomada dos trabalhos; reunião de um grupo de especialistas (2012) que desemboca na criação de um novo Grupo de Trabalho; criação da Comissão Especial de Estudos do Projeto de Sentenças e a conclusão de seus trabalhos na quarta e última reunião ocorrida em maio de 2018 passando o bastão agora para a Conferência Diplomática prevista para meados de 2019 para que seja aprovada a Convenção da Conferência da Haia sobre Reconhecimento e Homologação de Sentenças Estrangeiras de 2019.

A primeira reunião ${ }^{20}$ da Comissão Especial sobre o Projeto de Sentenças da Conferência da Haia foi de $01^{\circ}$ a 09 de junho de 2016, no Palácio da Paz, em Haia. ${ }^{21}$

Sobre o que se deu ao longo do ano de 2017, há que ser compulsado o relatório anual da Conferência da Haia sobre Direito Internacional Privado correspondente ao ano de $2017^{22}$, que em sua página 13, explana sobre as duas reuniões (em 2017) da Comissão Especial do Projeto de Sentenças, quais sejam: a segunda reunião, ocorrida de 16 a 24 de fevereiro de 2017 e a terceira (de 13 a 17 de novembro de 2017), relatório esse no qual é possível encontra-se um QR Code com pormenores a respeito das mesmas. A terceira reunião produziu o Projeto de Convenção sobre reconhecimento e homologação de sentenças estrangeiras (Projeto de Sentenças), de $2017 .{ }^{23}$

Por fim, a quarta e última reunião deu-se em maio de $2018 .{ }^{24}$ Vejamos.

\footnotetext{
${ }^{19}$ Para página que contém os links de interesse de todo o trabalho dessa Comissão, veja-se: COMISSÃO ESPECIAL SOBRE RECONHECIMENTO E EXECUÇÃO DE SENTEÇAS ESTRANGEIRAS. Special Commission on the Judgments Project (SCJP) - HCCH. Disponível em: https://www.hcch.net/en/projects/legislativeprojects/judgments/special-commission [acesso em 02/09/2018].

${ }^{20}$ Para um trabalho que foi escrito após essa primeira reunião, veja-se: ARAUJO, Nadia de; De NARDI, Marcelo. Projeto de Sentenças Estrangeiras da Conferência de Haia: Por um Regime Global de Circulação Internacional de Sentenças em Matéria Civil e Comercial. Journal of Institutional Studies, 2 (2016); Revista Estudos Institucionais, Vol. 2, 2, 2016, p. 707-735. Disponível em: https://estudosinstitucionais.com/REI/article/view/83/123 [acesso em: 09/09/2018].

${ }^{21}$ O Palácio da Paz foi sede da antiga Corte Permanente de Justiça Internacional quando da existência da Sociedade das Nações e hoje é sede da Corte Internacional de Justiça (ONU), o Tribunal Permanente de Arbitragem, a biblioteca do Palácio da Paz e também da Academia de Direito Internacional.

${ }^{22}$ CONFERÊNCIA DA HAIA SOBRE DIREITO INTERNACIONAL PRIVADO. Annual Report 2017. Disponível em: https://assets.hcch.net/docs/a0493ada-907e-48c3-bc85-0a880ee00d23.pdf [acesso em: 09/09/2018].

23 Esse Projeto de Sentenças encontra-se acessível em: CONFERÊNCIA DA HAIA SOBRE DIREITO INTERNACIONAL PRIVADO. COMISSÃO ESPECIAL SOBRE RECONHECIMENTO E EXECUÇÃO DE SENTEÇAS ESTRANGEIRAS (Special Commission on the Judgments Project). November 2017 Draft Convention. Disponível em: https://assets.hcch.net/docs/2f0e08f1-c498-4d15-9dd4-b902ec3902fc.pdf [acesso em 02/09/2018].

${ }^{24}$ A cronologia das reuniões é portanto a seguinte: $1^{\mathrm{a}}$, de 01 a 06/06/2016; $2^{\mathrm{a}}$ : de 16 a 24/02/2017; $3^{\mathrm{a}}$ : de 13 a 17/11/2017 e $4^{\text {a }}$ e última: de 24 a 29/05/2018. Marcelo de Nardi compareceu à essa reunião acompanhado pelo "diplomata Paulo Carneiro, o advogado da União Boni Soares, o procurador da República André de Carvalho Ramos, e os professores Doutores Nádia de Araújo, Fabrício Polido e Inez Lopes (UnB)”. In AJUFERGS (Associação dos
} 


\section{REUNIÃO DE 24 A 29 DE MAIO DE 2018}

Em 2018, o Conselho de Assuntos e Políticas Gerais da Conferência da Haia de Direito Internacional Privado congratulou-se com o progresso, que reputou ser muito bom, desse Projeto de Sentenças e determinou à Secretaria Permanente que desse continuidade na preparação para a quarta e última reunião final da Comissão Especial em maio de 2018. A Secretaria Permanente também foi encarregada pelo Conselho a fazer os preparativos para a realização de uma Conferência Diplomática em meados de 2019 e para uma nova reunião do Grupo de Peritos sobre questões relacionadas à jurisdição direta, logo após a conclusão da Conferência Diplomática. Assim, o próximo ponto já posto em pauta para futura negociação é justamente a discussão do tema jurisdição direta.

A quarta e última reunião da Comissão Especial, conforme já visto, ocorreu de 24 a 29 de maio de 2018 e produziu o Projeto de Convenção de 2018. ${ }^{25}$ A Comissão Especial considerou que completou a tarefa que lhe fora atribuída por mandato do Conselho e conforme reconhecido por este, entendeu que o Projeto de Convenção atingiu o ponto necessário para que se pudesse convocar, conforme já dito, uma Conferência Diplomática para meados de 2019. ${ }^{26}$

Pode-se perceber a evolução das negociações com o cotejo dos textos elaborados como resultado de cada uma dessas reuniões da Comissão Especial, ${ }^{27}$ bem como da análise do Relatório Explicativo de maio de $2018 .{ }^{28}$

Juízes Federais do Estado do Rio Grande do Sul). "Marcelo De Nardi participa de reunião na Conferência de Haia". Disponível em: https://www.ajufergs.org.br/noticia det.php?id=721 [acesso em 15/08/2018].

25 Para a agenda dessa quarta e última reunião, veja-se: CONFERÊNCIA DA HAIA SOBRE DIREITO INTERNACIONAL PRIVADO. COMISSÃO ESPECIAL SOBRE RECONHECIMENTO E EXECUÇÃO DE SENTEÇAS ESTRANGEIRAS (Special Commission on the Judgments Project). Draft Agenda for the Fourth Meeting of the Special Commission on Recognition and Enforcement of Foreign Judgments (24-29 May 2018). Disponível em: https://assets.hcch.net/docs/d698f24f-a0ed-419f-bc1b-a0cd71773741.pdf [acesso em 02/09/2018].

${ }^{26}$ A respeito, vide: CONFERÊNCIA DA HAIA SOBRE DIREITO INTERNACIONAL PRIVADO. COMISSÃO ESPECIAL SOBRE RECONHECIMENTO E EXECUÇÃO DE SENTEÇAS ESTRANGEIRAS (Special Commission on the Judgments Project). Special Commission on the Judgments Project: Overview of the Judgments Project. Disponível em: https://www.hcch.net/en/projects/legislative-projects/judgments. [acesso em 02/09/2018].

${ }^{27}$ Com esse desiderato de cotejo dos textos, seguem os links para cada um deles (todos esses links acessados em 13/08/2018):

- Link para o texto do Projeto, resultado da $4^{\mathrm{a}}$ e última reunião da Comissão Especial (maio de 2018): https://assets.hcch.net/docs/23b6dac3-7900-49f3-9a94-aa0ffbe0d0dd.pdf

- Link para o texto resultante $3^{\mathrm{a}}$ reunião (novembro de 2017): https://assets.hcch.net/docs/2f0e08f1-c498-4d15-9dd4$\underline{\text { b902ec3902fc.pdf }}$

- Link para o texto fruto da $2^{\mathrm{a}}$ reunião (fevereiro de 2017): https://assets.hcch.net/docs/d6f58225-0427-4a65-8f8b180e79cafdbb.pdf

- Link para o texto obtido da $1^{a}$ reunião (junho de 2016): https://assets.hcch.net/docs/42a96b27-11fa-49f9-8e48a82245aff1a6.pdf.

${ }^{28}$ Esse Relatório Explicativo Preliminar revisado (documento ${ }^{\circ}$ 10, de maio/2018: Judgments Convention: Revised Preliminary Explanatory Report) - já supra citado - foi feito pelos professores Francisco J. Garcimartín Alférez (Universidad Autónoma de Madrid) e Geneviève Saumier (McGill University - Canada), elaborado com base no texto do Projeto de Sentenças de novembro de 2017. Esse Relatório está disponível em: https://assets.hcch.net/docs/7cd8bc44-e2e5-46c2-8865-a151ce55e1b2.pdf [acesso em 20/08/2018]. Trata-se da versão revisada do Documento Preliminar n ${ }^{\circ}$ 7, de outubro de 2017 do Projeto de Sentenças (Preliminary Explanatory Report). 
Cumpre ainda noticiar, antes se de passar às considerações finais, o trabalho que veio sendo desenvolvido na UNCITRAL (Comissão das Nações Unidas sobre Direito do Comércio Internacional), pelo seu Grupo de Trabalho $n^{\circ} 5 .^{29}$

Esse Grupo de Trabalho debruçou-se sobre um Projeto de Lei Modelo ${ }^{30}$ a respeito do reconhecimento e execução de sentenças, especificamente no que tange às questões de insolvência, bem como seu Guia de Aplicação e Interpretação.

Esse Projeto de Lei Modelo - bem como seu Guia - foram aprovados pela UNCITRAL na sua $1080^{a}$ reunião, aos 02/07/2018, com o texto tal qual consta do Anexo III do Relatório apresentado na sua $51^{\mathrm{a}}$ sessão. ${ }^{31}$

\section{CONSIDERAÇÕES FINAIS}

Com todo o esforço de negociação e as inúmeras barreiras contornadas, num longo percurso que foi desde a constituição de um Grupo de Trabalho - que elaborou uma minuta da Convenção - até a constituição de uma Comissão Especial que realizou quatro reuniões com a elaboração de quatro Projetos sucessivamente negociados, espera-se êxito na Conferência Diplomática prevista para 2019.

Podemos assim sistematizar os objetivos a serem alcançados pela futura Convenção, de acordo com a Conferência da Haia:

- criação de um simplificado e seguro sistema de circulação internacional de sentenças;

- clareza nos requisitos necessários para a execução de sentenças estrangeiras;

- incremento do comércio e investimento;

- crescimento econômico;

- estabelecimento de garantias adequadas para a circulação de decisões judiciais;

- redução de custos transacionais pela padronização de práticas do comércio internacional;

- eliminar a necessidade de existência de processos em dois ou mais Estados;

- os demandantes passarão a ter maior clareza sobre onde será possível a execução de uma decisão estrangeira [RIBEIRO et al., 2016: 22-23].

29 A respeito desse Grupo de Trabalho, vide COMISSÃO DAS NAÇÕES UNIDAS SOBRE DIREITO DO COMÉRCIO INTERNACIONAL (UNCITRAL: United Nations Commission on Internacional Trade Law). Working Group V. Disponível em: http://www.uncitral.org/uncitral/en/commission/working_groups/5Insolvency.html [acesso em: 10/09/2018].

${ }^{30}$ Esse Projeto de Lei Modelo é composto por 16 artigos. O texto desse Projeto (Draft model law on recognition and enforcement of insolvency-related judgments), tal como já foi dito, pode ser compulsado no Anexo III (p. 63) do Relatório da UNCITRAL: UNITED NATIONS. Report of the United Nations Commission on International Trade Law, Fifty-first session (25 June-13 July 2018), General Assembly, Official Records, Seventy-third session, Supplement No. 17 (A/73/17). United Nations: New York, 2018. Disponível em: http://www.uncitral.org/pdf/english/commissionsessions/51st-session/Final_Edited_version_in_English_28-8-

2018.pdf [acesso em 10/09/2018].

Vide ainda, a respeito desse Projeto de Lei Modelo e seu Guia para Aplicação e Interpretação: COMISSÃO DAS NAÇÕES UNIDAS SOBRE DIREITO DO COMÉRCIO INTERNACIONAL (UNCITRAL: United Nations Commission on Internacional Trade Law). Insolvency. Disponível em: http://www.uncitral.org/uncitral/uncitral texts/insolvency.html [acesso em: 13/08/2018].

31 Sobre essa 51 $51^{\mathrm{a}}$ Sessão, vide COMISSÃO DAS NAÇÕES UNIDAS SOBRE DIREITO DO COMÉRCIO INTERNACIONAL (UNCITRAL: United Nations Commission on Internacional Trade Law). 51st Session. Disponível em: http://www.uncitral.org/uncitral/es/commission/sessions/51st.html [acesso em: 10/09/2018]. 
Como os trabalhos do Projeto de Sentenças, conforme já dito, evoluíram e tiveram êxito ao conseguirem superar diversos obstáculos que surgiram para que se conseguissem amoldar interesses divergentes dos Estados, podemos afirmar que os Estados que não resolverem fazer parte da vindoura Convenção, isso trará repercussão negativa para as transações comerciais das pessoas físicas e jurídicas implicadas, pois gerará insegurança jurídica, o que elevará os custos ou até inviabilizará essas transações.

\section{REFERÊNCIAS}

AJUFERGS (Associação dos Juízes Federais do Rio Grande do Sul). Marcelo De Nardi participa de reunião na Conferência de Haia. Disponível em:

https://www.ajufergs.org.br/noticia_det.php?id=721 [acesso em 15/08/2018].

ANZILOTTI, Dionisio. Studi di Diritto Processuale Internazionale e di Filosofia del Diritto. Padova: Cedam, 1963.

ARAUJO, Nadia de; De NARDI, Marcelo. Desafios para a circulação de sentenças (notícia de 20/04/2018 do Jornal Valor Econômico). Disponível em: https://www.valor.com.br/legislacao/5468453/desafios-para-circulacao-global-de-sentencas [acesso em: 09/09/2018]. Texto completo da notícia disponível em: https://alfonsin.com.br/desafios-para-a-circulao-global-de-sentenas/ [acesso em: 09/09/2018].

ARAUJO, Nadia de (et al.). Crônicas de direito internacional privado. Revista de Direito Internacional, Brasília, v. 14, nº 2, 2017, p. 9-16. Disponível em: https://www.publicacoesacademicas.uniceub.br/rdi/article/view/4863/pdf [acesso em: 08/08/2018].

ARAUJO, Nadia de; De NARDI, Marcelo. Crônica 1. Novidades de 2017 sobre circulação facilitada de sentenças estrangeiras. In ARAUJO, Nadia de (et al.). Crônicas de direito internacional privado. Revista de Direito Internacional, Brasília, v. 14, no 2, 2017, p. 9-16. Disponível em: https://www.publicacoesacademicas.uniceub.br/rdi/article/view/4863/pdf [acesso em: 08/08/2018].

ARAUJO, Nadia de; De NARDI, Marcelo. Projeto de Sentenças Estrangeiras da Conferência de Haia: Por um Regime Global de Circulação Internacional de Sentenças em Matéria Civil e Comercial. Journal of Institutional Studies, 2 (2016); Revista Estudos Institucionais, Vol. 2, 2, 2016, p. 707-735. Disponível em: https://estudosinstitucionais.com/REI/article/view/83/123 [acesso em: 09/09/2018].

ARAUJO, Nadia de. O STJ e a homologação de sentenças arbitrais estrangeiras: dez anos de atuação. In TIBURCIO, Carmen; VASCONCELOS, Raphael e MENEZES, Wagner (orgs.). Panorama do Direito Internacional Privado atual e outros temas contemporâneos: festschrift ao Professor Jacob Dolinger. Belo Horizonte: Arraes, 2015, p. 155-180. 
BRASIL. SUPERIOR TRIBUNAL DE JUSTIÇA. REGIMENTO INTERNO. Disponível em: https://ww2.stj.jus.br/publicacaoinstitucional/index.php/Regimento/issue/view/1/showToc [acesso em 26/09/2018].b

CARAMELO, António Sampaio. O reconhecimento e execução de sentenças arbitrais estrangeiras perante a Convenção de Nova Iorque e a lei da arbitragem voluntária. Coimbra: Almedina, 2016.

CARVALHO RAMOS, André de. Direito Internacional Privado e a Ambição Universalista. In TIBURCIO, Carmen; VASCONCELOS, Raphael e MENEZES, Wagner (orgs.). Panorama do Direito Internacional Privado atual e outros temas contemporâneos: festschrift ao Professor Jacob Dolinger. Belo Horizonte: Arraes, 2015, p. 14-33.

CIVININI, Maria Giuliana. Il roconoscimento delle sentenze straniere: artt. 64-67 L. N. 218/1995. Milão: Giuffrè, 2001.

COMISSÃO DAS NAÇÕES UNIDAS SOBRE DIREITO DO COMÉRCIO INTERNACIONAL (UNCITRAL: United Nations Commission on Internacional Trade Law). Insolvency. Disponível em: http://www.uncitral.org/uncitral/uncitral_texts/insolvency.html [acesso em: 13/08/2018].

COMISSÃO DAS NAÇÕES UNIDAS SOBRE DIREITO DO COMÉRCIO

INTERNACIONAL. Working Group V. Disponível em:

http://www.uncitral.org/uncitral/en/commission/working_groups/5Insolvency.html [acesso em: 10/09/2018].

COMISSÃO DAS NAÇÕES UNIDAS SOBRE DIREITO DO COMÉRCIO INTERNACIONAL. 51st Session. Disponível em:

http://www.uncitral.org/uncitral/es/commission/sessions/51st.html [acesso em: 10/09/2018].

COMISSÃO ESPECIAL SOBRE RECONHECIMENTO E EXECUÇÃO DE SENTEÇAS ESTRANGEIRAS. Special Commission on the Judgments Project (SCJP) - HCCH. Disponível em: https://www.hcch.net/en/projects/legislative-projects/judgments/special-commission [acesso em 02/09/2018].

CONFERÊNCIA DA HAIA SOBRE DIREITO INTERNACIONAL PRIVADO - site oficial (HCCH: Hague Conference on Private International Law). Disponível em: https://www.hcch.net [acesso em: 13/08/2018].

CONFERÊNCIA DA HAIA SOBRE DIREITO INTERNACIONAL PRIVADO. Annual Report 2017. Disponível em: https://assets.hcch.net/docs/a0493ada-907e-48c3-bc85-0a880ee00d23.pdf [acesso em: 09/09/2018].

CONFERÊNCIA DA HAIA SOBRE DIREITO INTERNACIONAL PRIVADO. CONVENÇÃO SOBRE OS ACORDOS DE ELEIÇÃO DE FORO. Disponível em: https://www.hcch.net/pt/instruments/conventions/status-table/?cid=98 [acesso em 09/09/2018]. 
CONFERÊNCIA DA HAIA SOBRE DIREITO INTERNACIONAL PRIVADO. Bibliography Related to the Judgments Project: draw up by the Permanent Bureau. Disponivel em: https://assets.hcch.net/docs/bd35517f-09ea-47d6-95ad-865d2c162504.pdf [acesso em: 09/09/2018].

CONFERÊNCIA DA HAIA SOBRE DIREITO INTERNACIONAL PRIVADO. COMISSÃO ESPECIAL SOBRE RECONHECIMENTO E EXECUÇÃO DE SENTEÇAS ESTRANGEIRAS (Special Commission on the Judgments Project). 2016 Preliminary Draft Convention. Disponível em: https://assets.hcch.net/docs/42a96b27-11fa-49f9-8e48-a82245aff1a6.pdf [acesso em $\underline{02 / 09 / 2018] \text {. }}$

CONFERENCIA DA HAIA SOBRE DIREITO INTERNACIONAL PRIVADO. February 2017 Draft Convention. Disponível em: https://assets.hcch.net/docs/d6f58225-0427-4a65-8f8b180e79cafdbb.pdf [acesso em 02/09/2018].

CONFERÊNCIA DA HAIA SOBRE DIREITO INTERNACIONAL PRIVADO November 2017 Draft Convention. Disponível em: https://assets.hcch.net/docs/2f0e08f1-c498-4d15-9dd4b902ec3902fc.pdf [acesso em 02/09/2018].

CONFERÊNCIA DA HAIA SOBRE DIREITO INTERNACIONAL PRIVADO. 2018 DRAFT CONVENTION Disponível em: https://assets.hcch.net/docs/23b6dac3-7900-49f3-9a94aa0ffbe0d0dd.pdf [acesso em 02/09/2018].

CONFERÊNCIA DA HAIA SOBRE DIREITO INTERNACIONAL PRIVADO. Special Commission on the Judgments Project: Overview of the Judgments Project. Disponível em: https://www.hcch.net/en/projects/legislative-projects/judgments. [acesso em 02/09/2018].

CONFERÊNCIA DA HAIA SOBRE DIREITO INTERNACIONAL PRIVADO. Judgments Convention: Revised Preliminary Explanatory Report (Fourth Meeting of the Special Commission on the Recognition and Enforcement of Foreign Judgments 24-29 May 2018). Disponível em: https://assets.hcch.net/docs/7cd8bc44-e2e5-46c2-8865-a151ce55e1b2.pdf [acesso em 20/08/2018].

CONFERÊNCIA DA HAIA SOBRE DIREITO INTERNACIONAL PRIVADO. Draft Agenda for the Fourth Meeting of the Special Commission on Recognition and Enforcement of Foreign Judgments (24-29 May 2018). Disponível em: https://assets.hcch.net/docs/d698f24f-a0ed-419fbc1b-a0cd71773741.pdf [acesso em 02/09/2018].

De NARDI, Marcelo. Controle indireto da jurisdição internacional: a "autoridade competente" na homologação de sentenças estrangeiras no Brasil. Revista da ESMAFE/RS (Escola Superior da Magistratura Federal do RS), no 1, Porto Alegre: ESMAFE/RS, 2017, p. 77-94. Disponível em: https://www.esmafe.org.br/web/docs/revista-28-07-17.pdf [acesso em 09/09/2018].

FRICKE, Martin. Die autonome Anerkenungszuständigkeitsregel im deutschen Recht des 19. Jahrhunderts: zugleich ein Beitrag zur Entstehungsgeschichte von § 328 Abs. 1 ZPO. Tübingen: Mohr, 1993. 
GRUENBAUM, Daniel. A construção histórica do Reconhecimento de Sentenças Estrangeiras. In TIBURCIO, Carmen; VASCONCELOS, Raphael e MENEZES, Wagner (orgs.). Panorama do Direito Internacional Privado atual e outros temas contemporâneos: festschrift ao Professor Jacob Dolinger. Belo Horizonte: Arraes, 2015, p. 205-218.

HARTLEY, Trevor; DOGAUCHI, Masato. Convention of 30 June 2005 on choice of court agreements: explanatory report. A Haia: Secretariado da Conferência da Haia sobre Direito Internacional Privado, 2005. Disponível em: https://assets.hcch.net/upload/expl37final.pdf [acesso em 20/08/2018].

INSTITUTO NACIONAL DA PROPRIEDADE INDUSTRIAL. Ministério da Indústria, Comércio Exterior e Serviços. INPI sedia debate sobre PI no projeto de sentenças estrangeiras. Disponível em: http://www.inpi.gov.br/noticias/inpi-sedia-debate-sobre-pi-no-projeto-de-regimeglobal-de-circulacao-de-sentencas [acesso em 09/09/2018]. Apresentação em power point disponível em: http://nadiadearaujo.com/wp-content/uploads/2017/09/INPI_1set17.pdf [acesso em 09/09/2018].

LOULA, Maria Rosa. Anotações sobre homologação de sentenças estrangeiras no Brasil. In TIBURCIO, Carmen; VASCONCELOS, Raphael e MENEZES, Wagner (orgs.). Panorama do Direito Internacional Privado atual e outros temas contemporâneos: festschrift ao Professor Jacob Dolinger. Belo Horizonte: Arraes, 2015, p. 195-204.

MOURA RAMOS, Rui Manuel. A Reforma do Direito Processual Civil Internacional. Coimbra: Coimbra Editora, 1998.

PINHEIRO, Luís de Lima. Estudos de Direito Internacional Privado: direito de conflitos, competência internacional e reconhecimento de decisões estrangeiras. Coimbra: Almedina, 2006.

PINHEIRO, Luís de Lima (org.). Seminário Internacional sobre comunitarização do Direito Internacional Privado: direito de conflitos, competência internacional e reconhecimento de decisões estrangeiras (realizado na Faculdade de Direito de Lisboa em 07 e 08 de maio de 2004). Coimbra: Almedina, 2005.

RIBEIRO, Gustavo Ferreira (et. al.). Crônicas de direito internacional privado. Revista de Direito Internacional, Brasília, v. 13, n.2, 2016, p. 2-20. Disponível em:

https://www.publicacoesacademicas.uniceub.br/rdi/article/view/4243/pdf [acesso em: 08/08/2018].

TEBBENS, Harry (et. al.). Internationale Zuständigkeit und Urteilsanerkennung in Europa. Colônia/Berlim/Bonn/Munique: Carl Heymanns Verlag, 1993.

TIBURCIO, Carmen; VASCONCELOS, Raphael e MENEZES, Wagner (orgs.). Panorama do Direito Internacional Privado atual e outros temas contemporâneos: festschrift ao Professor Jacob Dolinger. Belo Horizonte: Arraes, 2015.

UNITED NATIONS. Report of the United Nations Commission on International Trade Law, Fifty-first session (25 June-13 July 2018), General Assembly, Official Records, Seventy-third 
session, Supplement No. 17 (A/73/17). United Nations: New York, 2018. Disponível em: http://www.uncitral.org/pdf/english/commissionsessions/51stsession/Final_Edited_version_in_English_28-8-2018.pdf [acesso em 10/09/2018].

VIEGAS, Vera Lúcia. Harmonização Jurídica e Direito de Integração: elementos para uma teoria da Harmonização Jurídica. Tese (Doutorado). Faculdade de Direito - Departamento de Direito Internacional e Comparado - Universidade de São Paulo (USP), São Paulo, 2003. 